\title{
Update on devices and methods for the administration of intravenous antibiotics in a community setting
}

\author{
Glenna Germain RN BN MEd
}

$\mathrm{M}$ ultidisciplinary teams today strive to provide safe, effective, comfortable, satisfactory and cost effective care in a community setting for clients who require intravenous (IV) antibiotics. While the acuity level of the client has changed, so has equipment, and methods for the administration of IV antibiotics in a community setting have continued to evolve. Professionals must scan the marketplace for evolving and updated trends and pursue appropriate changes. With technological changes, a wealth of innovations presents themselves for appraisal. This task of evaluating new products is more manageable when they are classified into the following: skin preparation, IV cannulation, prevention of needlestick injuries, stabilization of venous access, nonelectronic delivery devices and electronic delivery devices. As many options as possible and the consequences of any changes must be considered. Any change in a community program must be tested before final implementation. To consider the impact of the new and potentially improved products for IV use in a community setting, one must first explore the current and future status of the market place.

\section{MARKET SIZE AND GROWTH FOR IV CATHETER DISPOSAL SYSTEMS}

Growth in IV catheter system disposables is remarkable: "The world wide dollar volume for IV catheter systems was es- timated to be $\$ 2.2$ billion for 1995." (1) The four product segments are as follows: standard IV access lines, peripherally inserted catheters (PICCS), central venous catheters (CVCs), and needleless access (1).

In $1995,87 \%$ of the worldwide market share for IV catheter sales was held by five companies: Baxter Health Care (Round Lake, Illinois) 22.4\%, IVAC (Richmond, British Columbia) $21.1 \%$, Abbott Laboratories Hospital Products Division (North Chicago, Illinois) 19.7\%, Advanced Medical (IMED) (Mississauga, Ontario) $17.6 \%$, McGaw (Essex, Ontario) $6.0 \%$ (1).

Market forecasts through to the year 2000 show a $23 \%$ increase for PICCs and midline catheters. The main factors affecting this increase are efforts to control costs, ease of use and lower infection risk (1).

Currently, PICCs, CVCs and midline catheters are mainly seen as critical care devices. Hence, marketing, sales and distribution efforts focus on critical care areas in hospitals (1).

Key issues and trends: The key issues and trends in this field include the miniaturization and ruggedness or durability of the electronics. This has led to the development of smaller, more accurate and easier to program ambulatory infusion pumps. This development induces safety, savings and client comfort, while allowing the transfer of treatment to sites outside the hospital (1). 
TABLE 1

New skin preparation products

\author{
Product \\ Topical anesthesia \\ Ametop (Smith + Nephew, Lachine, Quebec) (40) \\ Numby (IOMED, Salt Lake City, Utah)
}

\author{
Antimicrobials \\ Chorhexadine (Novopharm Ltd, Scarborough, Ontario) (42)
}

Persist PVP lodine/Alcohol PrepSwabs (43)

(Becton-Dickinson, Mississauga, Ontario)
Product features (claims)

Effectiveness is achieved in as little as 10 mins to a depth of $10 \mathrm{~mm}$ for peripheral or peripherally inserted catheters.

For use with a wide age range of patients (one month to over 65 years of age), the tetracaine content takes effect in 30 to 45 mins, lasts 4 to $6 \mathrm{~h}$ and anesthetizes up to $30 \mathrm{~cm}^{2}$ of skin. Vasoconstriction and vasospasm associated with other topical anesthetics (41) are less likely to occur.

More readily available in swabsticks and prep swab formats. Note that many centres are currently requesting the companies provide more user friendly unit dose packaging.

This is an iodine/alcohol prep swab. It has maintained low colony counts under clear moisture vapour permeable dressing for at least $120 \mathrm{~h}$ in an in vivo study. This eliminates a two-step procedure where drying is necessary after the iodine solution and again after the alcohol application. It comes conveniently packaged, with one swabstick to a package.
Market potential: Statistics compiled by Worldwide Research Advisory and Business Intelligence Services estimate that "during 1995, 1.9 million people received some form of IV therapy worldwide. Of these, an estimated 667,000 (35\%) of those individuals received their therapy at locations other than the hospital: outpatient clinic, surgical center, infusion center, oncology center, or a (nursing) home." (1)

Industry adaptation: "With greater demands for CVC and for PICC alternatives, product lines are likely to expand and marketing will become more aggressive. We are also likely to see an increase in the size of the sale forces with new product lines." (1) However, the approach to product evaluation by each home care team is governed by the overall goals of the specific program. Products that are chosen must ultimately enable or enhance the efficacy and safety of the treatment regime; the comfort and satisfaction of the client, significant others and/or family and program staff; and cost effectiveness.

How should the new, innovative and expanding plethora of devices be approached? As changes in old products and newly developed products lines are reviewed, it is important to pay close attention to the cirmstances of the milieu in the market and the desired features of each product, as well as, the individual program goals. A thorough understanding of how to integrate these two processes will assist the members of the community IV program staff as they review and update information relating to new or changed devices and methods for administration of IV antibiotics in a community setting. Products can be considered within the following categories: skin preparation; IV cannulation (peripheral, midline, and central); prevention of needlestick injury; stabilization of the venous access device; nonelectronic delivery devices; and electronic delivery devices.

\section{SKIN PREPARATION}

Topical anesthesia: Two products under the category of topical anesthesia are available (Table 1).
Antimicrobials: There are two products to consider in the category of antimicrobials: an old one which is regaining popularity; and a new combination product (Table 1).

\section{CANNULATION}

Peripheral venous access: Four new products attempt to minimize the known complications of peripheral cannulation (Table 2). The length of time that the peripheral line is in place is known to be directly proportional to the degree of thrombophlebitis experienced $(2,3])$. The goal is to use the smallest and shortest the cannula in as large a vein as possible to minimize the risk of thrombophlebitis (2).

Midline venous access: Midline catheters are those inserted into a peripherial vein, with the tip ending in the proximal portion of the arm (4). Midline (5), or midterm (6) catheters as they are sometimes called, appear to have a narrower range of application (7) than other choices for venous access. According to the Intravenous Nurses' Society, assessment for use is paramount because these catheters are inappropriate for many types of parenteral therapies (7). They seem to enhance the risk for complications such as thrombophlebitis (5-7). The Aquavene-based catheters, most notably the Landmark (8) (Menlo Park, California), have had hypersensitivity-like reactions associated with their use. This access method is less useful for community IV antibiotic programs than other methods. Four new midline catheters are available (Table 2).

PICCs: PICCs are inserted into a peripheral vein, with the tip residing in the vena cava (4). Given the nature of the antibiotics administered and the average lengths of therapy, PICCs for community venous access are a good choice. There are few complications with these lines over extended periods of time. One documented difficulty that rarely occurs is the 'stuck PICC' (9). This particular complication seems to be directly related to venospasm or phlebitis (9-11), rather than to a particular product line or medication. There are several catheters sold, many of which are open-ended lines. Some of these lines require heparin, while some may be saline locked. There is a wide vari- 
TABLE 2

New intravenous cannulation devices

\section{Product \\ Peripheral venous access devices \\ Angel Wing (Monoject, Sherwood Medical Company, St Louis, Missouri) \\ Insyte AutoGuard (Becton-Dickinson, Mississauga, Ontario) \\ Mednet (Narang Enterprises, New Dehli, India) \\ PROTECT IV PLUS (Johnson \& Johnson, Peterborough, Ontario) \\ Midline venous access devices \\ Accuquide PICC (B Braun, Bethleham, Pennsylvania) \\ Arrow PICC (Arrow Medical \\ Products, Mississauga, Ontario) \\ CliniCath (Sims Deltec Inc, St Paul, Minnesota) (50) \\ First MidCath (Becton-Dickinson)}

\section{Peripherally inserted central catheters \\ Arrow PICC (Arrow Medical Products)}

CliniCath (Sims Deltec Inc) (50)

Cook (Munroe House, Letchworth, Herfordshire, United Kingdom)

First PICC (Becton-Dickinson)

Groshong valved PICC (Bard, Salt Lake City, Utah)

per-Q-Cath (Geshco, San Antonio, Texas)

Splittocan (B Braun)

\section{Central venous access}

CliniCath (Sims Deltec Inc) (50)

Davol Implanted Ports (Davol, Cranston, Rhode Island)

L-Cath for Ports (Luther Medical Products, Tustin, California)

P.A.S. Port II (Sims Deltec Inc)

Port access noncoring needles Hubber class needles $(58,59)$ Gripper (Sims Deltec Inc)

VasTack (Gish, Irvine, California)
Product features (claims)

This is a new generation of butterfly infusion needle.

Becton-Dickinson claims that Vialon (Becton-Dickinson) reduces the risk of complications and has the further advantage of requiring little to no change in nursing insertion technique (44).

Narang claims that this product can be used safely without the risk of thrombophlebitis because it is made from plytetrafluroethylene, one of the most biocompatible materials known. Thin walls help it conform to client's veins. On the top, a valved medication port could negate the need for a stopcock. A porous filter, built into the hub, and a threaded stopper with luer lock allows for flashback but no spillage.

PROTECT IV PLUS is an intravenous catheter made from Ocrilion polyurethane. It is firm on insertion but softens once indwelling. Kinks recover quickly. A ' $V$ ' point enhances smooth insertion $(45,46)$.

This midline catheter has a peel away sheath and a Splittocan introducer that allows for clearer visualization $(47,48)$ during insertion.

This PICC is purported to be an alternative for intermediate type therapies. It is trimmable, has a peel away introducer and is available in a variety of sizes (49).

Advertisements claim that durability is enhanced by reinforcement in key areas such as the luer hub (51).

Becton-Dickinson claims this midline catheter has an introducer that has ergonomically designed finger grips for improved handling $(52,53)$.

Arrow advertises that they have responded to the critique of the insertionists. They tout: "a stylet free insertion to minimize trauma on insertion, a peel away introducer, and the catheter ability to soften and therefore enhance flow rates once they are in situ." An anchoring device is included (54).

This open-ended single lumen line is inserted with a guide wire that is reinforced in the key areas of stress to enhance durability.

Munroe House presents a single lumen silicone catheter with a peel away introducer. The package includes a guide wire and a winged extension set.

Becton-Dickinson provides the same ergonomically designed finger grips as used in its midline catheter. The company claims that the catheter undergoes a patented tipping process for a gentle smooth insertion. The breakaway sheath is lubricated to reduce trauma at the insertion site. Some may find that the integrated extension has an advantage for community clients because there is one less connection $(52,55)$.

The Groshong PICC has proven to be a successful venous access device for community programs. Its main advantage is that no heparin is required to maintain patency (56).

The per-Q-Cath/PICC or the 'lifeline' is an open-ended line. It is available either as a single or open-ended lumen line (56).

Braun claims the tear away sheath will minimize tissue and vessel trauma and improve comfort (47).

CliniCath is designed specifically for placement by an interventional radiologist. It has an external access port, available in 4 French and 5 French. Sizes and specific areas of the catheter are reinforced for long term wear and tear. The extension set is inherent in the line as is the clamp and anchor wing (51).

Davol Implanted Ports are still available in a variety of materials and port designs, but now they are available with either the Groshong catheter, featuring the three positioned valve or the open-ended Hickman catheter (57).

Produced with a preattached extension set, L-Cath for Ports has been found to be a successful safe and effective alternative access device for ports by reducing the number of restarts and extending the life of the portal septum (58).

Sims announces the availability on an ultra-low, lightweight, contoured design implantable port of titanium and polysulfone. P.A.S. Port II was developed for peripheral placement, yet it can be used to deliver the same therapies as chest-placed systems. Its design is both cosmetic and stable for access. $(51,59)$.

Hubber class needles range from the original forms to winged versions with or without extensions.

This comes within extension (with or without its optional sharp needle ' $y$ ' port ), the gelfoam padding and the removable 'pincher' handle.

This has similar characteristics to the Gripper

Choice is probably a matter of preference, but the product should fit smoothly to the skin surface and be stable $(58,61)$. PICCs, and midline and central venous catheters are good long term community lines because, if they occlude accidentally, they can be recanalized with fibrinolytic agents that clear clotted blood from veinous access devices (62) 
TABLE 3

Needlestick injury prevention devices

\begin{tabular}{|c|c|}
\hline Product & Product features (claims) \\
\hline $\begin{array}{l}\text { Clave Connector (ICU Medical Inc, san Clemente, } \\
\text { California) }\end{array}$ & $\begin{array}{l}\text { The Clave Connector is a simple one piece, swabable, needleless connector that does not } \\
\text { require caps or cannulas (63). }\end{array}$ \\
\hline $\begin{array}{l}\text { Tubex Blunt Pointe (Wyeth-Ayerst Canada Inc, } \\
\text { Saint-Laurent, Quebec)) }\end{array}$ & $\begin{array}{l}\text { The Tubex Blunt Pointe canula offer prefilled needleless cartridges in a range of products and } \\
\text { common sizes. Their claim is that it takes only half the force to inject an Interlink Injection } \\
\text { Site compound into insertion of the Interlink Blunt Cannula (64). }\end{array}$ \\
\hline $\begin{array}{l}\text { IV Key-Lok System (CardioMed Supplies Inc, } \\
\text { Gormley, Ontario) }\end{array}$ & $\begin{array}{l}\text { IV Key-Lok System sets have a key lock system that works with macro or micro, vented or } \\
\text { non-vented drip chambers. They cannot be used with other nonrelated equipment (65). }\end{array}$ \\
\hline $\begin{array}{l}\text { Interlink IV Access System (Baxter Health Care } \\
\quad \text { (Round Lake, Illinois) }\end{array}$ & $\begin{array}{l}\text { The Interlink IV Access System system employs a blunt plastic cannula (syringe cannula, lock } \\
\text { cannula (threaded lock cannula) and a preslit injection site. Vial adapters and blood draw } \\
\text { assemblies are available. There is no valve mechanism to stick or leak (66). }\end{array}$ \\
\hline $\begin{array}{l}\text { Needleless System (IVAC, Richmond, } \\
\text { British Columbia) }\end{array}$ & $\begin{array}{l}\text { The IVAC Needleless System employs a valve that prevents needle access. Normal priming } \\
\text { technique primes this line, which is accessed with a luer lock connection and, while not } \\
\text { in use, with a cap. }\end{array}$ \\
\hline Needle Lock Device (Baxter) & $\begin{array}{l}\text { This device is used instead of a needle to attach a secondary or piggy back line to a primary } \\
\text { set. It twins and locks onto luer compatible y-sites, so it cannot be easily pulled put. }\end{array}$ \\
\hline $\begin{array}{l}\text { Protect IV Plus (Johnson \& Johnson, } \\
\text { Peterborough, Ontario) }\end{array}$ & $\begin{array}{l}\text { Protect IV Plus employs a retractable needle that is sheathed with a trigger after use (67). This } \\
\text { is a sensible alternative when peripheral blood draws are required. }\end{array}$ \\
\hline Smart Site (Alaris, Basingstoke, United Kingdom) & $\begin{array}{l}\text { Smart Site is a needleless and capless system compatible with existing equipment; a luer } \\
\text { connection and positive pressure opens the valve port. The valve automatically closes } \\
\text { when the luer connection is removed (68). }\end{array}$ \\
\hline
\end{tabular}

Systems with less potential for sticking shut or leaking would be wise choices for the community, especially in terms of infection control

ety in choice of sizes, as well as lumens (single or double lumen). The wide ranges of choice reflect increasing use (Table 2).

Central venous access: For many clients on community IV antibiotics, CVCs are the only appropriate venous access. They are generally dependable and stable over the long term. They can be surgically implanted catheters with external access or surgically implanted ports requiring 'needling in' to an internal access. Port access non-coring needles are produced in a variety of styles (12).

\section{PREVENTION OF NEEDLESTICK INJURY}

Total quality management constantly looks for ways to improve processes by continually evaluating systems, identifying root causes, and providing employees with training, resources and empowerment. "Risk management involves the identification and analysis of risks, development of action plans to deal with the risk, examination of the financial issues, and constant evaluation of the system." (13) There has been a great deal published on this subject $(6,14-22)$ - suffice it to say that attending to the market and demanding that the market respond to this safety need is imperative.

Many options are available for the prevention of needlestick injuries (Table 3).

\section{STABILIZATION OF VENOUS ACCESS}

When considering stabilization of venous access devices in the community setting, the following questions should be asked.

- Would moisture sealed in (23) be counterproductive from a skin breakdown point of view? From a community standpoint, would it likely require extra nursing visits to change this more frequently?
- Does the frame (23) around the film enhance the application to the site and become obstructive and difficult to handle? Does it have a tendency to rip off unevenly and obstruct the draping process necessary to seal all around a line to provide effective anchoring?

- If gloves are required, are nonlatex gloves the last choice? N-Dex (Best Manufacturing, Menlo, Georgia) (25) advertise that "they do not cause latex allergies and they are three times more puncture proof than latex" (25).

Community programs generally use two methods for the stabilization of the venous access device. The first of the two methods is a sterile adherent dressing, which seals down firmly around the line (is pinched around the line), while at the same time holding the line firmly down against the skin once the skin has been properly assessed, cleaned and left to dry. The use of transparent polyurethane dressing versus gauze dressings is supported in the literature (26-28). Other devices, classified as catheter anchoring or securing devices, are available. They are available either as a component of the line and supplied with the catheter in the original packaging, or as an optional item sold separately. Other innovations include the development of catheter-holding devices to enhance a client's ability to become more able to administer the drugs to his or herself (28). Gloves may be necessary for the aseptic handling of the line (25) (Table 4).

\section{NONELECTRONIC DELIVERY DEVICES}

Nonelectronic ambulatory devices have been available for quite some time. They are still appropriate for community programs from an operational point of view in some circumstances. Table 5 provides information on new devices. 
TABLE 4

Stabilization of venous access

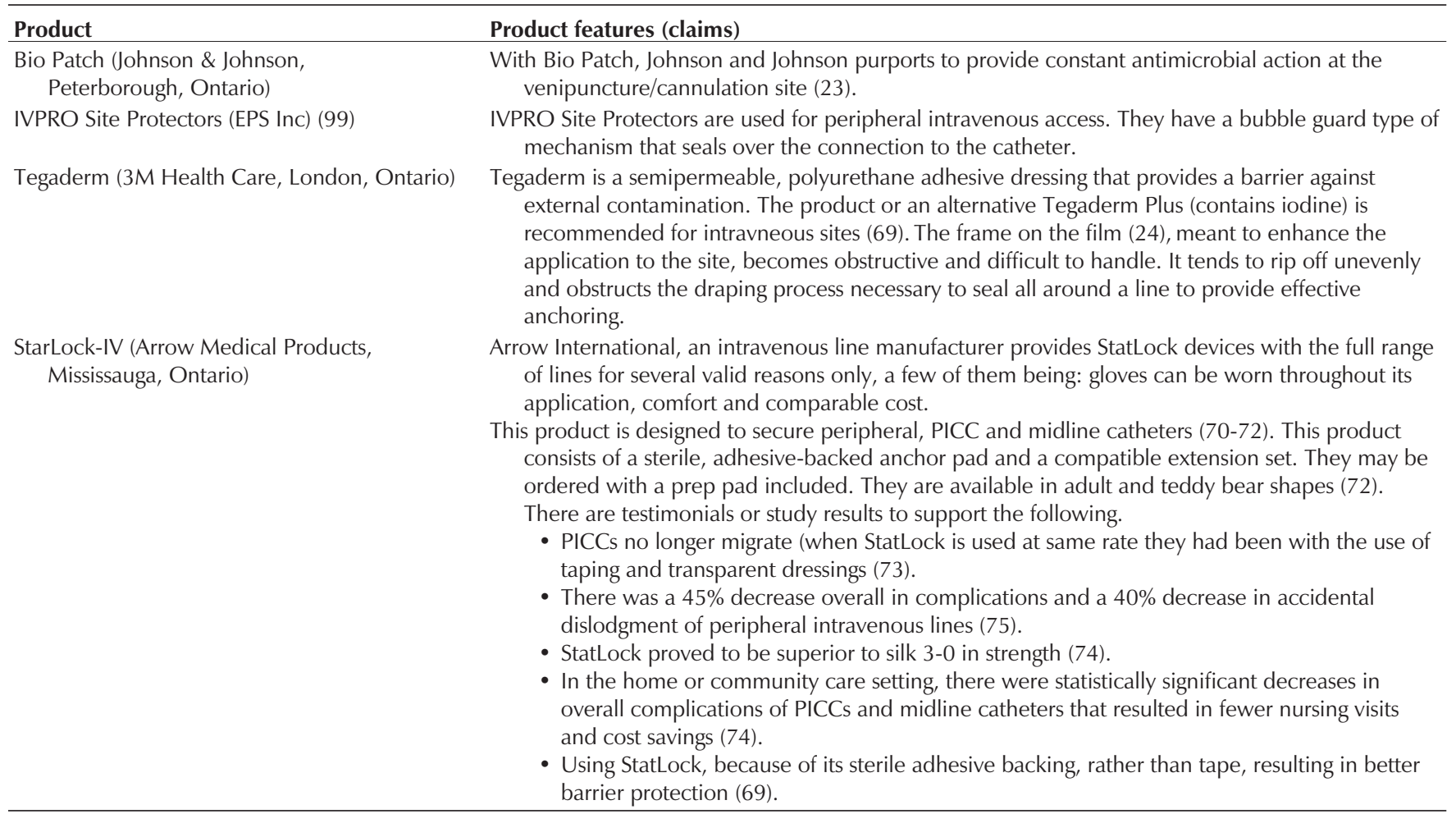

TABLE 5

Nonelectronic delivery device

\begin{tabular}{|c|c|}
\hline Product & Product features (claims) \\
\hline $\begin{array}{l}\text { Infusor System (Baxter Health Care, Round Lake, } \\
\text { Illinois) }\end{array}$ & $\begin{array}{l}\text { This is a disposable, fixed rate system. Volumes are restricted to between } 65 \text { and } 275 \mathrm{~mL} \text {. } \\
\text { While simple and discreet, each container is discarded after use }(75,76) \text {. }\end{array}$ \\
\hline $\begin{array}{l}\text { Paragon Ambulatory Pump (Solo Pak } \\
\text { Pharmaceuticals, Inc, Boca Raton, Florida) }\end{array}$ & $\begin{array}{l}\text { This spring-driven Paragon Ambulatory Pump with tubing control delivers } 0.5-200 \mathrm{~mL} / \mathrm{h} \text {. This } \\
\text { is a resilient, reusable pump }(100,000 \text { doses) that is environmentally friendly. Clients find } \\
\text { it is discreet to carry in a fanny pack }(77,78) \text {. }\end{array}$ \\
\hline $\begin{array}{l}\text { SideKick (I-Flow Corporation, Lynx Medical Products, } \\
\text { Mississauga, Ontario) }\end{array}$ & $\begin{array}{l}\text { The \#50, } 100 \text { or } 200 \text { SideKick Ambulatory Pump is another spring driven device that has } \\
\text { tubing control and delivers 50, 100, or } 200 \mathrm{~mL} / \mathrm{h} \text {. This, too, is a reusable pump, but it is } \\
\text { different than the Paragon because it has a Y connector allowing simultaneous delivery of } \\
\text { two compatible medications. It is environmentally friendly and discreet to carry. }\end{array}$ \\
\hline
\end{tabular}

Community programs would likely prefer recyclable/reusable options. All of these devices have approximately plus or minus $15 \%$ margin of error. This may not be acceptable for the delivery of antibiotics relying on 'peaks' or those relying on rigid rate control for proper therapeutic effect

\section{ELECTRONIC DEVICES}

Infusors: Infusors or "infusion regulation devices for IV therapy come in many makes and models. There are various gravity control devices, volumetric pumps, peristaltic pumps, syringe pumps, and recently small portable pumps for home care" (30) (Table 6).

Ambulatory pumps: "Several articles have reported the efficacy, safety and cost effectiveness of the home IV antibiotic therapy. The development of a computerized ambulatory infusion pump has enabled us [members of the community IV therapy program team] to treat patients previously considered ineligible for home IV antibiotic therapy." (31) This statement was made in 1989, and remains true today. However, it is a more acute or complex client requiring care in 1998. Newer generations of therapeutic devices and more models of pumps have allowed therapy options to expand. Some choices are: Medical Delivery Devices The Maxx 250 (Baxter Health Care); Alaris Rhythmic Portable Infusion Pump (Alaris, Basingstoke, United Kingdom); Graseby 9000 Series Ambulatory Infusion Pumps (Graseby Medical Ltd,Watford, Hertfordshire, United Kingdom); EZ Flow 480 Multi-Therapy Infusion Pump (Gish Biomedical Inc, Irvine, California); Abbott Aim Ambulatory Infusion Manger; INVACARE MedMate 1100 (INVACARE Infusion systems, San Diego, California); Deltec New CADD PLUS (Sims Deltec Inc, St Paul, Minnesota); Sims Deltec The CADDPRIZM VIP; MED-O-GENIC Sabratek 6060 Homerun (MED-OGENIC, Montreal, Quebec) and IVAC SPACESAVER. All of the pumps fall in approximately the same price range. With the ex- 
TABLE 6

Electronic devices

\begin{tabular}{l}
\hline Product \\
Infusors \\
Dual Rate Infusor (Baxa, Englewood, \\
Colorado) \\
Excelsior Syringe Pump (Healthmark Ltd, \\
Montreal, Quebec) \\
FREEDOM 60 Syringe Infusion System \\
(ProMed Systems Inc, Chester, New York) \\
Multichannel pumps \\
MedSystem III (IVAC, Richmond, British \\
Columbia) \\
Stratus (McGaw, Essex, Ontario)
\end{tabular}

Disposable pump

Microject (Salt Lake City, Utah)

\section{Product features (claims)}

This has two rates of flow. It accommodates syringes from 5 to $100 \mathrm{~mL}$, and can be pole mounted or carried.

This device accommodates syringes up to a volume of $50 \mathrm{~mL}$. This is a relatively simple device that allows for syringes to be mounted with one of three speeds to be selected as per pharmacist/drug administration order (72).

This device provides a uniform flow rate, takes up to a $60 \mathrm{~mL}$ syringes, and can be discreetly carried.

MedSystem III weighs about $1.33 \mathrm{~kg}$ but allows for three independent channels.

McGaw is working on trials with the Stratus Ambulatory Infusion System. This will likely be the first ambulatory pump with a three channel capacity (79). For community-based intravenous antibiotic therapy, this will solve the dilemma of delivering two medications that are not compatible but on different dosing schedules to the nonself care client because the third channel can carry a normal saline solution.

Microject is a family of single patient procedure specific pumps with vastly simplified controls (80). This meet the needs of the American insurance companies that find the $\$ 75$ or so worth paying; and they do not need to worry about equipment retrieval or having to deal with the terminal cleaning issues between clients. The margin of safety is about plus or minus $15 \%$.

Ongoing evolution of filters and their in-line use helps to promote safety from the risk of air embolism (81)

ception of the spacesaver, which is nearly $1.33 \mathrm{~kg}$, the others range between 392 and $476 \mathrm{~g}$. They are all ambulatory, and, except for the Maxx and the CADD Plus, they can be programmed in several modes and can deliver rates in the range of $1 \mathrm{~mL}$ (sometimes less) to 350 to $500 \mathrm{~mL} / \mathrm{h}$. The margin of safety is roughly $5 \%$ to $6 \%$. There are two multichannel pumps to discuss (Table 6).

\section{SUMMARY}

Administration of IV antibiotics in the community has continually evolved over the past several years $(32,33)$. In today's complex home care environment, it requires thoughtful, planning and careful consideration of issues, including the multidisciplinary team required to safely, comfortably and cost effectively keep clients who need IV antibiotics at home. Most important, devices have changed over tim,e with technological advances allowing heath care teams to broaden the scope of care to the client (34-37). Understanding that the market is responding to the upward trend for the support of community IV antibiotic programs and that we may be overwhelmed with multiple new choices, caution is necessary. Carefully consider all the scenarios and possible consequences $(38,39)$. Initially, trials should be performed rather than adopting or accepting change at face value, because what may work advantageously in one arena may not in another.

\section{REFERENCES}

1. The World Wide Market for Vascular Access Catheters and Intravenous Accessories". www.findsvp.com/tocs/ML0246.HTM. Accessed March 22, 1998.

2. Lundgren A, et al. Peripheral intravenous lines: Time in situ related to complications. J Intravenous Nurs 1996;19:229-38.

3. Wright A. Reducing infusion failure: A pharmacologic approach A review. J Intravenous Nurs 1996;19:89-97.

4. Canadian Intravenous Nurses Association. Intravenous Therapy Guidelines, 2nd edn. North York: Canadian Intravenous Nurses Association, 1999.

5. Lacy DE, et al. Comparison of two percutaneous intravenous midline" catheters in cystic fibrosis. J Intravenous Nursing 1996;19:28-31.

6. Jagger J, et al. Injuries from vascular access devices - High risk and preventable. J Intravenous Nurs 1997;20(Suppl 6S):S33-9.

7. Intravenous Nurses Society. Position Paper: Midline and Midclavicular Catheters. J Intravenous Nurs 1997;20:175-8.

8. Vanek VW, et al. Hypersensitivity-like reactions related to insertion of Aquavene-based midline and PICC catheters. J Intravenous Nurs 1997;20:23-7.

9. Intravenous Nurses Society. Position paper: Peripherally inserted central catheters. J Intravenous Nurs 1997;20:172-4.

10. Marx M. The management of the difficult peripherally inserted central venous catheter line removal. J Intravenous Nurs 1995; 18:246-9.

11. Wall JW, et al. Peripherally inserted catheters: Resistance to removal - A rare complication. J Intravenous Nurs $1995 ; 18: 251-4$.

12. Kawasumi Laboratories America - Port Access Infusion Sets. J Intravenous Nurs 1997;20:56. [Advertismement]

13. Murphy D. The development of a risk management program response to the spread of bloodborne pathogen illness. J Intravenous Nurs 1995;18(Suppl 6S):S43-7.

14. Hibberd, Pat L. Patients, needles and healthcare workers. J Intravenous Nurs 1995;18(Suppl 6S):S22-31.

15. Intravenous Nurses Society. Position Paper: Safety Products. J Intravenous Nurs 1996;19:69-70.

16. Pugliese G. Reducing risks of infection during vascular access. J Intravenous Nurs 1997;20(Suppl 6S):S11-23.

17. Purtilo RB. Ethical issues in the handling of bloodborne Pathogens: Evaluating the occupational safety and health administration bloodborne pathogen standard. J Intravenous Nurs 1995;18(Suppl 6S):S38-S42.

18. Tereskerz P. Legal implications of needlestick injuries. J Intravenous Nurs 1997;20(Suppl 6S):S25-S32.

19. Thomas CS. Management of infectious waste in the home. J Intravenous Nurs 1997;20:188-92.

20. Williams HF. Integrating the occupational safety and health administration mandates onbloodborne pathogens in the practice setting. J Intravenous Nurs 1995;18(Suppl 6S):S9-16.

21. Wiseman GR. The Impact of the Occupational Safety and Health Administration Regulations on Management Decision Making Strategies. J Intravenous Nurs 1995;18(Suppl 6S):S3-8.

22. Home Intravenous Antibiotic Therapy Using a Programmable Infusion Pump". www.thriveonline.com/health/Library/ CAD/abstracts2528.html. Accessed March 22, 1998.

22. Johnson $\&$ Johnson Medical Inc. - New BIO Patch Antimicrobial 
Dressing.J Intravenous Nurs Nov/Dec 1995, 18:6:inside front cover. [Advertisement]

24. 3M Health Care - Tegederm Transparent Dressings. J Intravenous Nurs 1996;19:228. [Advertisement]

25. Best Manufacturing - N-DEX Non Latex Exam Gloves. Menlo: Best Manufacturing, January 1998.

26. Lau CE. Transparent and gauze dressings and their effect on infection rates of central venous catheters: a review of past and current literature. J Intravenous Nurs 1996;19:240-5.

27. Madeo M. A randomized study comparing IV 3000 (transparent polyurethane dressing) to a dry gauze dressing for peripheral intravenous catheter sites. J Intravenous Nurs 1997;20:253-6.

28. Treston-Aurand J, et al. Impact of dressing materials on a central venous catheter infection rates. J Intravenous Nurs 1997;20:201-6.

29. Wisconsin Alumni Research Foundation - Catheter Holding Apparatus. www.wisc.edu/warf.boi/pg3029us.html. Accessed March 22, 1998.

30. Phillips LD. Manual of I.V. Therapeutics. Philadelphia: FA Davis Company, 1993.

31. Home Intravenous Antibiotic Therapy Using a Programmable Infusion Pump". www.thriveonline.com/health/Library/ CAD/abstracts2528.html. Accessed March 22, 1998.

32. Treston-Aurand J, et al. Impact of dressing materials on a central venous catheter infection rates. J Intravenous Nurs 1997;20:201-6.

33. Corbett S. Intravenous modalities in the treatment of bloodborne pathogen illnesses: Antibiotics, antifungals, and antivirals. J Intravenous Nurs 1995;18(Suppl 6S):S17-1.

34. Campbell K. Intravenous nursing services. J Intravenous Nurs 1996;19:35-7.

35. Coulter K. Nurses transition from hospital to home: bridging the gap. J Intravenous Nurs 1997;20:87-93.

36. Dugger B. Intravenous Nurses Competency: Why Is It Important? J Intravenous Nurs 1997;20:287-97.

37. Trask K. The challenges of teaching universal precautions to multicultural, diverse patients and their family members. J Intravenous Nurs 1995;18(Suppl 6S):S32-7.

38. Lowe-Phelps K. Managing change while maintaining quality in home infusion therapy. J Intravenous Nurs 1996;19:38-45.

39. Robertson KJ. The Role of the I.V. Specialist in Health Care Reform. J Intravenous Nurs 1995;18:130-46.

40. Smith + Nephew Inc. Ametop Gel Changes the Way Needles Feel. Lachine: Smith and Nephew, Inc, 1998.

41. Bahruth AJ, et al. Peripherally inserted catheter insertion problems associated with topical anaesthesia. J Intravenous Nurs 1996;19:32-4.

42. Novopharm Ltd. Chlorhexidine Usage Form. Scarborough: Novonpharm Ltd.

43. Becton-Dickinson - Persist PVP Iodine/Alcohol Prep Swabs. J Intravenous Nurs 1997; 20:58. [Advertisement]

44. Becton-Dickinson - Introducing Insyte Autoguard Shielded I.V. Catheters. January, 1998. [Advertisement]

45. Johnson $\&$ Johnson. Vascular Access: Safety is the Point. Peterborough: Johnson and Johnson Medical Products, 1995.

46. Johnson and Johnson Medical Inc. - PROTECT IV PLUS IV Catheter Safety System. J Intravenous Nurs 1995;18:129. [Advertisement]

47. B Braun Medical Inc. The New Accuguide PICC. J Intravenous Nurs 1996;19:246. [Advertisement]

48. B Braun Medical Inc. - The New Accuguide PICC and Midline Catheter. J Intravenous Nurs 1997;20(4):inside front cover. [Advertisement]

49. The Arrow Midline Catheter. www.arrowintl.com/new products.html. Accessed March 22, 1998.

50. Customer and Clinical Services. CliniCath Peripherally Inserted Catheter. St Paul: Sims Deltec Inc, 1996.

51. Sims Deltec, Inc. Introduces A New Interventional Radiology PICC - CliniCath IR Catheters; Sims Deltec, Inc. Launches the P.A.S. Port II ${ }^{R}$ System - The Second Generation in Peripheral Access; Sims Deltec, Inc. Aquires Graseby Medical Inc. all from www.deltec.com/new.html. Accessed March 22, 1998.
52. Becton-Dickinson - First PIIC. J Intravenous Nurs 1996;19:282. [Advertisement]

53. Becton-Dickinson - When it comes to infusion therapy, we have a lot of strong points J Intravenous Nurs 1998;21(15):back cover.

54. Arrow International - Take Your PICC. J Intravenous Nurs 1996;19:283.

55. Becton-Dickinson - There's a Lot of Support Behind Our Infusion Therapy Products. J Intravenous Nurs 1998;21(15):inside front cover. [Advertisement]

56. Bard Access Systems - Assessment Advantage Program. J Intravenous Nurs 1997;20(2):inside back cover. [Advertisement]

56. Davol Implanted Ports: Use and Maintenance. Salt Lake City: Davol:1-16.

58. Brown JM. Evaluation of a Polymer Implanted Port Access Device. J Intravenous Nurs 1996;19:303-6.

59. Sims Deltec - P.A.S. PortII System. J Intravenous Nurs 1997;20:208. [Advertisement]

60. Its Safety Intravenous Catheter Insertion Devices. www.pathfinder.com/money/latest/press/PW/1998Feb23/1670.ht ml. Accessed March 22, 1998.

61. Gish Biomedical, Inc. Hemed Infusion Systems: Vas Tack. Irvine: Gish Biomedical Inc, 1996.

62. Abbott Laboratories Salvage 9 Out of 10 Occluded I.V. Catheters. J Intravenous Nurs 1996;9:285-288. [Advertisement]

63. ICU Medical Inc. Clave Connector. J Intravenous Nurs 1995;18:239. [Advertisement]

64. Wyeth-Ayerst Laboratories - Tubex Blunt Pointe. J Intravenous Nurs 1995;18(5):back cover. [Advertisement]

65. Cardio-Med Supplies, Inc. I.V. Sets With Key-Lok ${ }^{\mathrm{TM}}$ System. Gormly: Cardio-Med Supplies Inc, 1995.

66. Baxter Health Care Corporation. Interlink I.V. Access System. Round Lake: Baxter Health Care Corporation, Becton-Dickinson and Co, January 1997

67. Johnson \& Johnson Medical Inc. PROTECT IV PLUS IV Catheter Safety System. J Intravenous Nurs 1998;21:15. [Advertisement]

68. Smart Site. Basingstoke: Alaris Medical Systems January, 1998.

69. SMTL Dressing Data Cards: Tegaderm. www.smtl.co.uk/WMPRC/DataCards/HTML/tegaderm.html. Accessed March 22, 1998

70. About Venetec. http://www.ventec.com/about_ventec.html. Accessed March 22, 1998.

71. Venetec Products: StatLock Product Categories. http://www.venetec.com/products.html. Accessed March 22, 1998.

72. Venetec International - StatLock: The Science of Securement. J Intravenous Nurs 1997;20(6):inside front cover. [Advertisement]

73. Deltec Introduces New Multi-Use Pump - The CADD PRIZM ${ }^{\mathrm{TM}}$ VIP. www.deltec.com/new.html. Accessed March 22, 1998.

74. a) Comparative study of two securement techniques for short peripheral i.v. catheters (StatLock IV); Retrospective analysis for picc and midlines in the home care setting. www.venetic.com/research.html. Accessed March 22, 1998.

75. Baxter Health Care Corporation, I.V. Systems Division. Meeting A Broader Range of Therapeutic Needs: The Infusor System. Round Lake: Baxter Health Care Corporation, 1996.

76. Baxter Health Care Corporation. The Infusor System. Round Lake: Baxter Health Care Corporation, 1994.

77. Flow Corporation. The Paragon Ambulatory Pump. I-Flow Corporation. Irvine: Flow Corporation, date unknown.

78. SoloPak Pharmaceuticals Inc. - Things To Do, Places To Go, and People To See. J Intravenous Nurs 1995;18:245. [Advertisement]

79. McGaw Inc. Stratus Ambulatory Infusion System. Irvine: McGaw, Inc, 1995.

80. Microject. Microject - Family of Procedure Specific Pumps. Microject. Salt Lake City: Microjet.

81. B. Braun Medical Inc. - The New Filter Flow Positive Charged Super Filter. J Intravenous Nurs 1996;19:227. [Advertisement] 


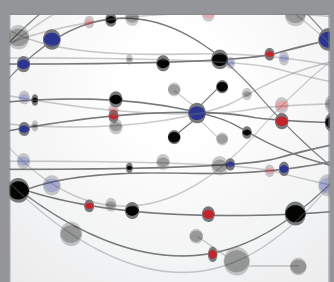

The Scientific World Journal
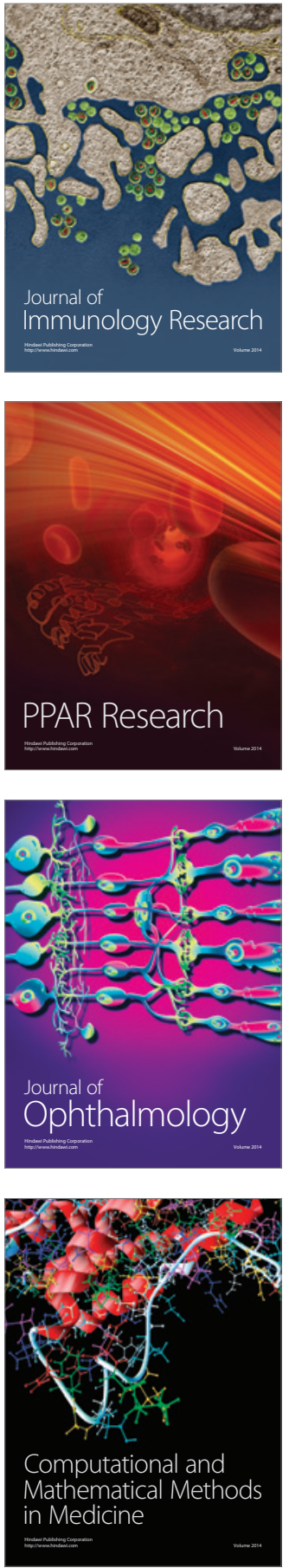

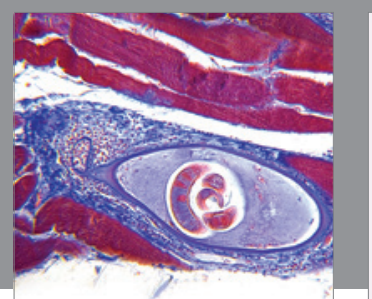

Gastroenterology Research and Practice

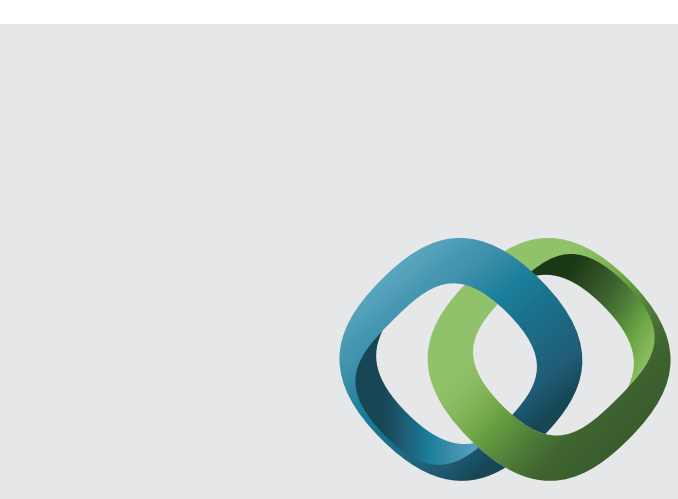

\section{Hindawi}

Submit your manuscripts at

http://www.hindawi.com
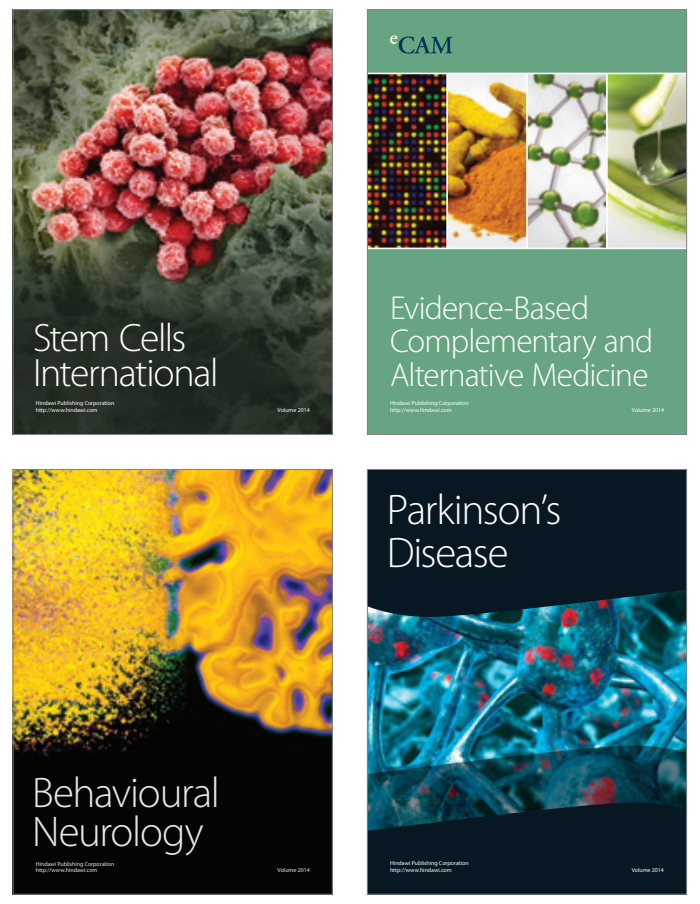
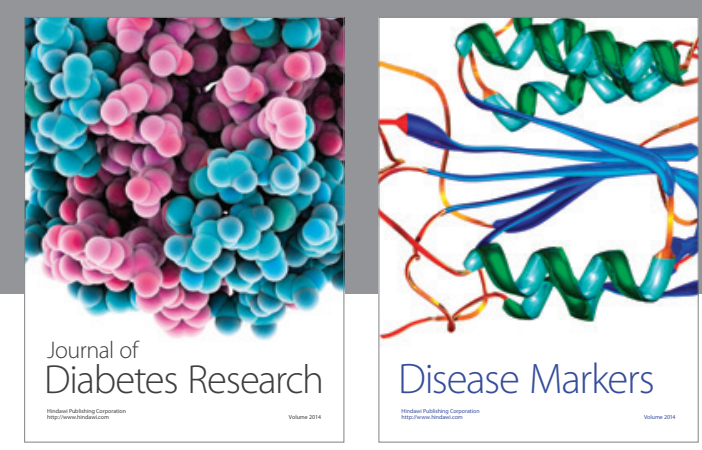

Disease Markers
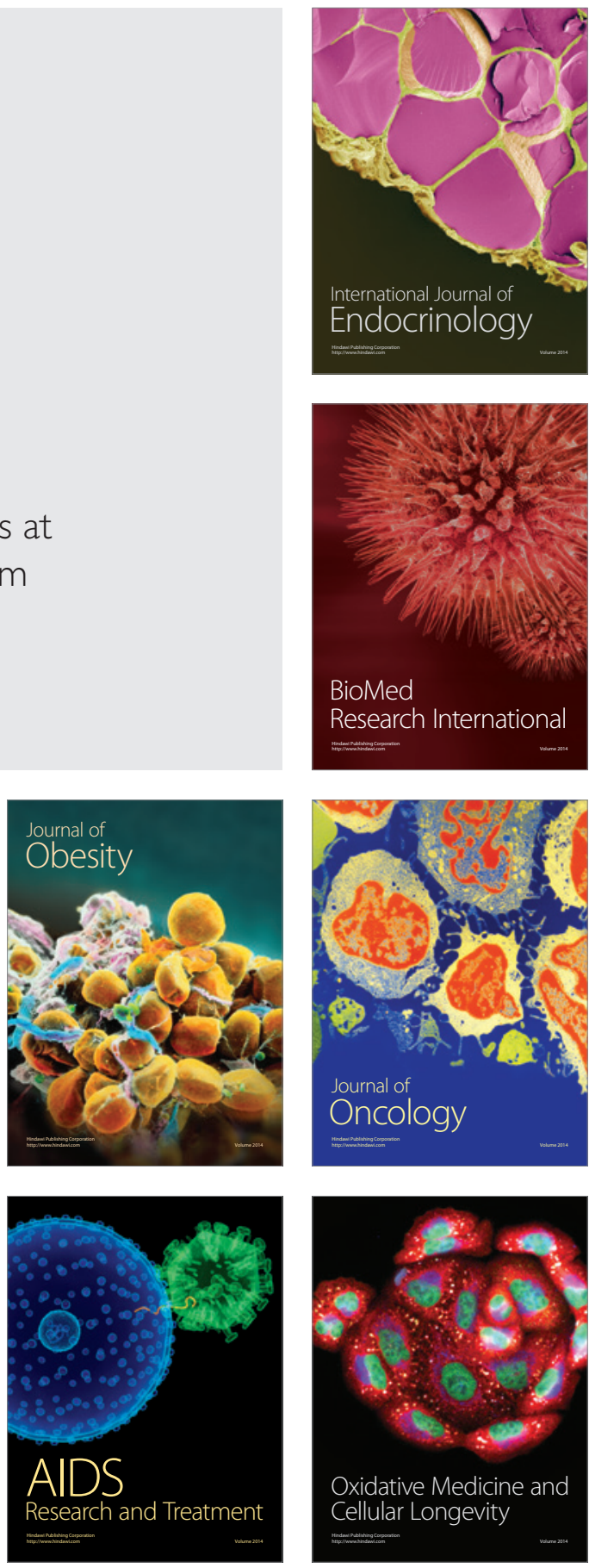